\title{
The Expression By Vendors Of Tanah Lot Temple Area, Bali In Oral Communication With Foreign Tourist
}

\author{
Kadek Adi Indra Brata and Mirsa Umiyati \\ \{adibrata418@gmail.com\} \\ Pusat Pengelolaan Jurnal, Universitas Warmadewa, Denpasar, Bali-Indonesia
}

\begin{abstract}
This research aims to analyze the function and types of expression used in communication especially by vendors in Tanah Lot Temple area. The area is choice because Tanah Lot is one of the tourism objects that have many local people become vendors, so with such conditions, it can be seen direct interaction between local people and foreigner. This research applied field research method by looking directly the interactions between the vendors and tourist at the field. The data used in this research were oral English conversations between the vendors and the tourist that is taken by recorded and a note. The method applied in analyzing the data was descriptive method. The data were described descriptively by categorized them according to their respective types and functions. As a result of analysis, it was found that there are six functions of expression, there are; greeting, offering, giving, requesting, refusing, thanking and saying goodbye. Moreover, the types of expression were informal, neutral and formal expressions.
\end{abstract}

Keywords: Oral Communication; Expressions; Vendors

\section{Introduction}

The use of English expression in tourism sector certainly has a very significant influence. Therefore, it can be assessed the quality of human resources which become actors of tourism in an area. Usually, the problem for everyone in using English is due to the inability to consider foreign accents, ignorance of taboo words, inadequate vocabulary and grammar knowledge. The expression is one of the important means of conveying social messages in people's lives. Leo Jones in his book entitled Function of English New Edition [1] states that there are many expressions in English, there are; greeting, offering, giving, requesting, refusing, thanking and saying goodbye. In term to the research, there will be just some expressions that will be given more emphasis in relation to English function commonly used by vendors' attendant. [2] states that the three most relevant functions in using English are providing information, accepted by provide services and provide assistance. These three functions are certainly a necessity for people who wants to work directly in the tourism sector in order to establish well communication with the tourist. 
In Bali, almost some Balinese people work in the tourism sector. Especially, Balinese local people who live in a tourist area, being a vendor which is one option as a job. One of the tourism destinations that have many local people who become a vendor is in Tanah Lot temple area. The number of the native English speaker and foreign people that can speak English usually come to visit Tanah Lot in great quantities every year. After reviewing the location, it becomes problems that faced by the vendors in communicating with the tourist. In this case the vendors usually communicate with the tourists with informal English. This is because they still do not understand about the use of grammar and good language governance, for example: "welcome sir, look looking". This answer is informal English because this response does not have good form grammar. To make this vocabulary good, there are alternative vocabulary words such as "Good morning, good morning, welcome, sir, please see?" In general, English grammar they usually use is not in accordance with good grammar, but they can communicate well. In English communication, various conversational functions are usually found. In this case the speaker involved in communication does not know English well. Similar things were also found by [3] on their research to vendors in the Legian Kuta area, Bali. They found vendors in legian use four types of language styles in communication and the language style most often used is informal language style. From these findings, it can be concluded that almost all vendors learn English by self-taught or daily environment, so that informal language styles can inherit naturally to them. This opinion is supported by the result of [4] research in Borobudur, Yogyarkarta. She found the vendors of Borobudur Temple have limited English knowledge; they did not master the English vocabulary and sentence pattern. The vendors studied the English language without getting the formal education. They study English communication by their experience in Borobudur temple and also asked to the tourist guide if they had any problems in English communication.

Based on background above, the objectives of this research are to analyze the types and functions of English expressions used by the vendors at Tanah Lot temple area in Communication with Foreign Tourist.

\section{Methods}

This research applied field research method. This method is used in a research that conducted systematically by raising existing data in the field [5]. The data used in this research were English conversations between the vendors and the tourist. There were some expressions used as the data source of this research. The data is collected by recording and note taking. The conversation of vendors and tourist were recorded and the data were adjusted to the topic. The data were analyzed by applying descriptive method. The goal of descriptive research is to describe a phenomenon and its characteristics [6]. Based on this quote, the data are described descriptively categorized according to their respective types and functions.

\section{Results And Discussion}

When the vendors were speaking with their customers, there were some English expressions that found in colecting the data. The functions of English expressions that found were: greeting, offering something, giving price, requesting, refusing, thanking, and saying goodbye. Furthermore, the explanation is described in the following discussion. 


\subsection{Greeting}

Greeting is the expressions that said for the first time to greet someone or other people although they don't know each other. According to Firth (1973) as cited in [7] greeting phenomena as ritual consists of verbal and non-verbal forms. Verbal and Non-verbal form is usually used in terms of gender and social status as contextual variable. However, in [8] research that used student as an object of research, he found the students used different greeting expression and words formation according to social status of interlocutor. He found the students tend to use solidarity politeness to show their desire to set up of equality, intimacy and common interest but still keep distance. In this research, it was found that greeting expressions is used by the vendors to greet the tourist. Almost all the conversations of the vendors with the tourists begin with greeting expressions. The vendors usually greeted the tourist when they for the first time met them walk in Tanah Lot area. This fact indicates that the vendors express the functional expressions. Their way of using greeting English expressions is already in a fluent way.

The following are some expressions used by vendors in their conversation with the tourists showing greeting function:

Conversation 1:

Vendor

: Good afternoon Mate, you got some kite? Playing bird from rubber brand.

Tourist : : Thank you, tomorrow.

Vendor : Got one?

Tourist : (silent and go way)

The underlined words show the greeting function. The vendor used this function when he met the tourist walk in Tanah Lot area at afternoon, so he said "Good afternoon" to the tourist, then with smiling face greeted the tourist while offering their product. This expression belongs to formal greeting because he also used the word "mate" to feel closer or more friendly to the tourist for the sake that he could offer his product with a hope that the tourist would buy it. Such as kind of greeting is mostly used by the vendors in Tanah Lot, and they can say it fluently. The purpose of using this expression is to attract the tourist so that they can offer their product.

Conversation 2:

Vendor $\quad: \underline{\text { Hallo }}$ Madam, would you like buy kite?

Tourist : : sorry...?

Other expression that was mostly used was "hallo". The word "hallo" in the conversation above shows that the vendor used greeting function. The vendor used this function to greet the tourist when he met in the first time. From the conversation, the vendor expressed this function is an informal way because he used the function in informal situation. He used an informal greeting "hallo" to greet the tourist but he also used the word "madam" to complete the expression in friendly way and good attitude. The purpose of this expression is to start the conversation while the vendor would offer their product to the tourist.

Conversation 3:

Vendor $\quad:$ Excuse me, miss! Buy one please yah?

Tourist : No thank you!

The words "excuse me" in the conversation above belong that the vendor used greeting function. The vendor used this function when she greeted the tourist with a hope to offer her product. She expressed this function in a formal expression because she used a formal greeting "Excuse me" to greet the tourist in formal situation and she also used the word "miss" to express this function in a good attitude, but the tourist was not interested in the vendor 
product. The purpose of using this function is to greet the tourist with a hope the tourist was interested in her offering.

From the three examples of conversation above, it can be concluded that the expressions used by some vendors still use informal types. That is because some vendors want to foster a sense of intimacy with tourists. The vendors also do not arbitrarily to choose which tourists will be greet using informal expressions, based on data in the field, the vendors will greet young tourists with informal greetings, but use formal greetings to tourists who are adults/old.

\subsection{Offering Something}

Offering something is one of English functions used to offer something to other people. Based on the research done, the expression found of offering something used by vendor in Tanah lot Area to offer their product. They usually offered their product with informal expressions because their English was still influenced by Indonesian language, but if we see it from their purpose of offering something to other people it was still understood by the tourist. So the bargaining activities could be done well. The Vendor usually offered their product when the tourist came from the gate of Tanah Lot area, there were even some vendors offered their products in parking area. They offered their product while persuading and showing their product to the tourists with a hope the tourists were interested in their product.

In the following conversation, there are some expressions used by vendors with the tourists showing offering function.

Conversation 4:

Vendor : Hallo Madam, would you like buy kite?

Tourist : sorry...?

Vendor : kite, buy kite...?

Tourist : No thank you...!

Vendor : oh oke...

The underlined sentence in the conversation above belongs to offering function. The vendor came and offered kite to the tourist, but the tourist didn't look interested in the product. Seen from the conversation, the sentence "would you like buy kite" belongs to informal function because the sentence is not correct grammatically. The sentence should be "would you like to buy kite, please?", as we know this expression was done with a smile and friendly manner. The purpose of the conversation tells us that the vendor offered kite to the tourist but the tourist was not interested in it.

Conversation 5:

Vendors : maybe you like something? You can try!

Tourist : yeah, but that not enough!

Vendors : oh no problem we have big size, which one do you want maybe?

Tourist : this one, but just to see!

Vendors : ya ya (laugh), no problem!

Tourist : thank you!

Other expression that was mostly used that I have found in the research as offering something function was "maybe you like something? You can try". The vendor asked the tourist to try her merchandises. Seen from the conversation, the vendor expressed this function in an informal expression because she used this expression in an informal situation and the sentence was not correct grammatically. The formal expression should be "would you like to try something?" and it could be in good attitude if she added "madam" in her ending of conversation. But it was still understood by the tourist and the vendor expressed this function in friendly manner and with a smile. 
Conversation 6:

Vendor : Looking-looking, mom. I have many souvenir. This is good for you. Please try, mom!

Tourist : (silent shake of head)

The expression "looking-looking, mom" above belongs to offering something function because the underlined words above also show that the vendor offered something to the tourist. The expression that the vendor used in this conversation is an informal expression (Looking-looking, mom) because this expression is different from the formal expression that was seen in the theory. Usually, based on the theory the expression should be "would you like to have a look, mom" or "have a look, please". Although it was informal, still the vendor could communicate with the tourist well. And he treated the tourist in friendly way. What was more important is the selling of the products could run well.

Conversation 7:

Vendor : Playing kite sir?

Tourist : (no respond)

The underlined sentence in the conversation above belongs to offering function. In this case the vendor offered a kite to the tourist. The vendor invited the tourist to play a kite with a hope the tourist would be interested with it, but the tourists looked not interested with his offered. The expression used for offering something was "playing kite sir?", if we look at the conversation the expression belongs to informal expression, because he just say "playing", the formal expression should be changed into "would you like to try it?" or "would you like to try it?" And his expression was done in a friendly way and good attitude.

\subsection{Giving Price}

Giving price is the expressions used to give the information about the price of something to someone. Based on the research done, the giving price function is usually used when the tourist wanted to know about the price of product were sold by the vendor. Sometimes, there are many bargaining processes in this situation when the tourist didn't agree about the price of the products that they wanted. Then with smiling face the vendor gave the second price that made the tourist interested in it. Most vendors expressed this function in informal expression.

The following are some expressions used by vendors in their conversation with the tourists showing giving price expression:

Conversation 8:

Vendor : That's ten thousand, twenty thousand, two one !

Tourist : Twenty, is expensive, we have to go to there one.

Vendor : : Another one give you thirty thousand.

Tourist : No, other one give me fifteen. Yes !

Vendors : : Are you kidding me? (laugh)

Tourist : No!

The expression underlined in the conversation above shows that the vendor used giving price function. Seen from the conversation the vendor expressed "that's ten thousand" as giving price function. Seen from the words used, this expression belongs to formal expression because he used grammatical English. At that time the vendor expressed the giving price function fluently. He also expressed it in a friendly way and with a smile. The conversation tells us about the vendor gave the price of rubber kite that the tourist wanted to buy, and the tourist bargain the rubber kite to the vendor, and then they agreed the price and the tourist bought it.

Conversation 9: 
Tourist : fifteen? (pointed the kite)

Vendor $\quad:$ Ya, just fifteen ! That's ten thousand ( pointed the money )

Tourist $\quad:$ ( the tourist pay by sixteen thousand )

Vendor : I no have changed

Other expression belongs to giving price function was "just fifteen". In this case the tourist pointed and asked about the price of his product, and the vendor gave the price of the product that the tourist wanted to buy, the tourist agree with the price without bargaining. The Vendor used the shortest form of giving price "just fifteen", but it was still understood by the tourist. The vendor expression belongs to informal expression, because the formal expression should be "that's price is fifteen thousand, mom" but this expression done in good attitude and friendly way. The purpose of this expression is to give price to the tourist that they ask about the price of his product.

Conversation 10:

Vendor : Yes mom, how much?

Tourist : No thanks.

Vendor $\quad$ : I give you local price, ten thousand for one. One dollar, sir!

Tourist : (go away)

The expression "ten thousand for one" belongs to giving price function. In this case, the vendors gave price to the tourist with a hope the tourist was interested in the products after he said the price. Seen from conversation, the vendor expression belongs to informal expression because he just said " ten thousand for one", the formal expression should be "that's price ten thousand for one pieces, sir". But the vendor could communicate with the tourist well and in friendly way. The purpose of expression in the conversation is to tell the tourist about price of the souvenir but the tourist was not interested in the souvenir and went away.

\subsection{Requesting}

Requesting function is used when we want someone to do something. In my research, I could see that the vendor used the requesting function when they requested the tourist to do something. This function was usually used when the vendor requested the tourist to try their product. Most of them used this function in an informal expression, but it was done in friendly manner.

Conversation 11:

Vendors : open the wing, and put your finger inside, and then you twist the rubber one, throw up, so until enough this rubber. Alright!

Tourist : This?

Vendor : : Ya, and then you throw again, $\underline{\text { So }}$ try !

The underlined sentence above belongs to requesting function. The conversation shows that the vendor requested the tourist to try the kite, with a hope the tourist would buy his product. The vendor used this function when they requested the tourist to try his product. The vendor expression "so try" belongs to informal expression, because he expressed it without formal element. The formal expression should be "please try the kite", although he expressed this function belongs to informal expression, the tourist still understood what he meant. His expression was done in friendly way and with a smile. But this expression could be better if he said the formal element "mom" or "please". So the formal expression should be "please try the kite, mom!". The purpose of this expression is to request the tourist to try his product.

Conversation 12:

Vendor $\quad$ : Looking-looking, mom. I have many souvenir... This is good for you... Please try, mom ! 
Tourist : ( silent shake of head $)$

The expression "please try, mom" above belongs to requesting function. In this case, the vendor requested the tourist to try the souvenir who passed by their stall. From the conversation the expression "please try, mom" belongs to formal expression, because he expressed it with formal element "please" and the word "mom" ended his expression. His expression was mentioned in a friendly manner and with smile. The purpose of this expression is to attract the tourist with a hope the tourist would buy his product.

\subsection{Refusing}

Refusing is one of English functions used when someone wants to refuse someone opinion. Based on the data that I found, this function was usually used by the respondents. The expression of refusing which were usually used by the respondent such as:

- Sorry!

- No!

The expressions are informal. Although all of the expressions are informal, the respondent can communicate well with the tourist. Their communication is running well. The purpose of this function is to refuse someone opinion. The respondents mentioned this function in good attitude and friendly way. It can be proved with the following conversation.

Conversation 13:

Tourist

Vendor

: How much this one?

Tourist

Twenty five thousand rupiah sir, maybe you like?

: yes I like, but twenty five thousand to expensive for me! How about ten thousand?

Vendor

Tourist

: I am so sorry, that's to low. Twenty thousand for you.

Vendor

: No ! bye bye.

: bye bye.

The underlined sentence in the conversation above belongs to refusing function. The vendor used this expression when the tourist wanted to buy kite. In this conversation the vendor gave price to the tourist, but the tourist didn't agree about the price that the vendor gave to him. The tourist bargained it but the vendor refused about the price that the tourist wanted. Seen from its formality, the expression "I am so sorry, that's to low" belongs to informal form because it happens in informal situation and it was mentioned for the sake that the vendor felt close with the tourist. But at that time the vendor refused the price from the tourist. The conversation above tells us about the vendor refused about the bargained price from the tourist.

Conversation 14:

Vendor

Tourist

: you like hair plait, mom? Cheap price just ten thousand

Vendors

Tourist

: No, lose $\underline{\text { me! }}$

Vendor

: please!

Tourist

: eight thousand last price!

Vendor

: ok I buy this one.

Tourist

: thank you so much.

Other expression that I found in this research was "No, lose me!". The expression "No, lose me" above belongs to refusing function. In this case the vendor used the refusing function after he didn't agree with the price that the tourist wanted, but the tourist bargained her product and the vendor agree with the bargaining from the tourist. This function belongs to 
informal expression because the sentence is not correct grammatically. Although it was informal, the vendor could communicate with the tourist in friendly way and smile. The purpose of this expression tells us that the tourist used refusing function to refuse the vendor offered and she respected the vendor with an answer "No, thank you".

\subsection{Thanking}

Thanking is the expression used to thank to somebody. It usually comes after the talking and before we say goodbye to other we talk with. During the research, I found many expressions that were used by the vendor when they said thanks to the tourist. The expression can be seen as follows:

Conversation 15:

Tourist

Vendor

: Ya, Ok!

Tourist

: open the pack, and you can put in the bag!

Vendor

: thank you

Tourist

: I have a bag, maybe

Vendor

: Oh its ok. Thank you very much

: thank you very much

The underlined sentence is classified as thanking function. Because we see that the expressions used by the tourist to say "thank you very much" to the vendor and the vendor also say "thank you very much" to respond. This expression belongs to neutral expression because this expression could be used in any situation and commonly used by anybody when he or she had finished the talking with others, or when they had something from others. This was the mostly used by the vendor or tourist before they ended the conversation. The conversation tells us that the tourist used thanking function after she bought a kite from the vendor.

Conversation 16:

Tourist

: that's good

Vendor

: thank you so $\underline{\text { much }} ! \underline{\text { and }}$ have $\underline{\text { a nice }} \underline{\text { day }}$

Tourist

: you too!

Vendor

: good luck to you, and thank you for the bargain (laugh). Ok, see you, byee !

The expressions "thank you so much! And have a nice day" above belongs to thanking function. Seen from the word underlined in the conversation this expression belongs to neutral expression because the expression could be used anytime and in any situation. Still the vendor usually used this expression to anybody when they finished the conversation. In this case the vendor say "thank you very much" to the tourist after she bought his product. The purpose of this expression is to say thank to the tourist after she bought his product

\subsection{Saying goodbye}

Saying goodbye always comes at the end of a conversation and before we separate with somebody. When I was doing the research on Tanah lot, the vendor used many expressions to say goodbye.

Conversation 17:

Tourist

: that's good

Vendor

: thank you so much ! and have a nice day

Tourist

: you too!

Vendor

: good luck to you, and thank you for the bargain (laugh). Ok, see you, byee ! 
The underlined sentence above shows the saying goodbye function. The expression "see you" was used by the vendor when they have to farewell with the tourist. The expression belongs to neutral expression, because the expression could be used anytime and to anybody. Besides, his express the expression with smile and feel friendly. The purpose of this expression is to say goodbye to the tourist and its usually used in the end conversation. In this case the vendor say goodbye to the tourist after the tourist bought kite to him.

Conversation 18:

Tourist

Vendor

: How much this one?

Tourist

: Twenty five thousand rupiah sir, maybe you like?

: yes I like, but twenty five thousand to expensive for me!

How about ten thousand?

Vendor

Tourist

: I am so sorry, that's to low. Twenty thousand for you.

Vendor

: No! bye bye.

: bye bye.

The expression "bye bye" above shows the saying goodbye function. The tourists always say "bye bye" when they have to farewell with other people. The tourist used neutral expression to express that function because this function could be used in any situation and also could be used to any people. The expression was done in good attitude and friendly manner. The purpose of this expression is tells us to say goodbye function after he didn't agree about the price which was given by the vendor.

\section{Conclusions}

Based on the analysis, it can be noted some points as conclusion related the problems observed in this research. There are some expressions functioning as greeting, the expressions found are good afternoon Mate, hallo Madam, and Excuse me. The expressions functioning as offering something are would you like buy kite, Looking-looking, mom, playing kite sir. The expressions functioning as giving price are That's ten thousand, just fifteen, ten thousand for one. The expressions functioning as requesting are so try, Please try mom. The expressions

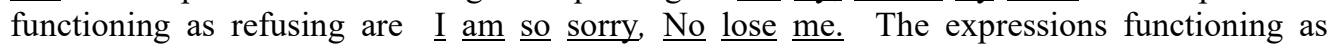
thanking are thank you so much, thank you very much. The expressions function as saying goodbye are see you, bye bye. The types of expressions are used by the vendors in applying the functions of English expressions that can be found in this research were: informal, neutral and formal expressions. Most vendors used an informal expression although there were some vendors using the formal expression in applying the English function. Besides, grammatically, their English is not good, but communicatively they can communicate with the tourist well. All of vendors in Tanah lot area looked very patient and tried to keep smiling, familiar and so friendly when they served the tourist.

\section{References}

[1] L. Jones, Functions of English. Cambridge: Cambridge University Press, 1977.

[2] N. Prachanant, "Needs Analysis on English Language Use in Tourism Industry," Procedia - Soc. Behav. Sci., vol. 66, no. December, pp. 117-125, 2012.

[3] R. Sidabutar and I. G. Sadia, "Language Functions and Styles Used by Vendors at Legian Beach,” J. Humanis, Fak. Ilmu Budaya Unud, vol. 22, no. 1, pp. 156-160, 2018. 
[4] V. Mandarani, "Cooperative Principle used by the Vendors of Borobudur Temple in Communication with Foreign Tourists," in The 4th International Conference on Language, Society and Culture in Asian Contexts, 2017, pp. 319-325.

[5] S. Arikunto, Dasar-Dasar Research. Bandung: Tarsoto, 1995.

[6] H. Nassaji, "Qualitative and descriptive research: Data type versus data analysis," Lang. Teach. Res., vol. 19, no. 2, pp. 129-132, 2015.

[7] K. E. Williams, "An Evaluation of Greeting Exchanges in Textbooks and Real Life Settings," 2001 .

[8] Bukhori, "Expression of Greetings by Indonesian EFL Learner," Indones. J. Integr. English Lang. Teach., vol. 2, no. 1, pp. 1-11, 2016. 